Int. J. Electrochem. Sci., 15 (2020) 4117 - 4126

\title{
Electrochemical Corrosion Behavior of Ni-doped ZnO Thin Film Coated on Low Carbon Steel Substrate in 3.5\% NaCl Solution
}

Duo Zhang, Mingming Wang, Nan Jiang ${ }^{*}$, Yan Liu, Xiaonan Yu, Haobo Zhang,

School of Mechanical Engineering, North China University of Science and Technology, Tangshan, China

*E-mail: jiangnansci@ aliyun.com

doi: $10.20964 / 2020.05 .25$

Received: 1 January 2020 / Accepted: 23 February 2020 / Published: 10 April 2020

A facile sol-gel technique was successfully used to deposit $\mathrm{Ni}$-doped $\mathrm{ZnO}$ thin film on low carbon steel substrates for evaluation of electrochemical corrosion resistance. The morphology, composition and crystalline phase of the coatings were obtained by scanning electron microscopy, energy dispersive X-ray spectroscopy, X-ray diffraction and atomic force microscopy. The evaluation of corrosion protection was carried out by potentiodynamic and electrochemical impedance spectroscopy analysis in $3.5 \% \mathrm{NaCl}$ solution. The electrochemical results show that the uniform and thick coatings of Ni-doped $\mathrm{ZnO}$ thin film as an insulator indicated higher resistances and lower capacitances than other samples. The assessment of coating thickness influences on corrosion protection revealed that the sample with $454 \mathrm{~nm}$ thickness had a lower corrosion current density and higher corrosion potential than that of the other samples, indicating a better performance in corrosion resistance.

Keywords: Ni-doped $\mathrm{ZnO}$; Corrosion resistance; Low carbon steel; Sol-gel technique; Electrochemical study

\section{$\underline{\text { FULL TEXT }}$}

(C) 2020 The Authors. Published by ESG (www.electrochemsci.org). This article is an open access article distributed under the terms and conditions of the Creative Commons Attribution license (http://creativecommons.org/licenses/by/4.0/). 